\title{
Meta
}

Journal des traducteurs

Translators' Journal

\section{The Linguistic Significance of Lexical Items in the Case of Conference Interpretation from English to Japanese}

\section{Yasuko Obana}

Volume 38, numéro 3, septembre 1993

URI : https://id.erudit.org/iderudit/003752ar

DOI : https://doi.org/10.7202/003752ar

Aller au sommaire du numéro

Éditeur(s)

Les Presses de l'Université de Montréal

ISSN

0026-0452 (imprimé)

1492-1421 (numérique)

Découvrir la revue

Citer cet article

Obana, Y. (1993). The Linguistic Significance of Lexical Items in the Case of Conference Interpretation from English to Japanese. Meta, 38(3), 491-501. https://doi.org/10.7202/003752ar
Résumé de l'article

Il est généralement admis que le message transmis par l'interprète ri est pas une reproduction intégrale de l'original, mais le produit de l'analyse de celui-ci. Les élèves-interprètes éprouvent souvent de grandes difficultés à trouver le mot juste pour réexprimer le message dans la langue-cible. L'analyse linguistique des fautes de vocabulaire permet de déterminer les sources d'erreurs et, partant, d'améliorer la pédagogie de l'interprétation. 


\title{
THE LINGUISTIC SIGNIFICANCE OF LEXICAL ITEMS IN THE CASE OF CONFERENCE INTERPRETATION FROM ENGLISH TO JAPANESE
}

YASUKO OBANA

University of Queensland, Brisbane, Australia

\begin{abstract}
Résumé
Il est généralement admis que le message transmis par l'interprète n'est pas une reproduction intégrale de l'original, mais le produit de l'analyse de celui-ci. Les élèvesinterprètes éprouvent souvent de grandes difficultés à trouver le mot juste pour réexprimer le message dans la langue-cible. L'analyse linguistique des fautes de vocabulaire permet de déterminer les sources d' erreurs et, partant, d'améliorer la pédagogie de l'interprétation.
\end{abstract}

\section{INTRODUCTION}

It is the general consensus in the interpretation research field that interpretation does not mean that whatever the speaker delivers will be re-stated in another language. In transmitting a message the interpreter must first understand what the speaker means in the context, and then convey his message in a re-constituted form which clarifies the speaker's underlying meaning. This approach is evident already in note taking. Seleskovitch (1978) mentions that "in consecutive interpretation you do not jot down all the details of the unprocessed information... but instead you note the results of your meaning analysis" (p. 39). A similar approach is suggested by Hu (1990) that "the interpreter is ... [supposed] to be flexible in generalizing and extracting the principal idea of the said discourses..." (p. 85). He calls this the Abstract Interpreting Approach (AIA). Larson's (1984) skewing, though used in translation, aims at the same skill.

The approach above extends to the level of vocabulary selection in the target language. Not only should messages be conveyed, but the appropriate selection of vocabulary should also conform to a given context.

From the experience of training students in the Interpretation Course (from English to Japanese), it has been notable that they often fail to choose appropriate words in the target language. Messages are conveyed and the audience of the target language would manage to guess their meaning. This means that those selected words are within the domain of meaning the message forwards, i.e. their cognitive (conceptual or denotational) meaning is achieved, but those words are not precise in terms of their contextual, connotational or social meaning. This would not be considered to fully accomplish interpretation.

The present paper is concerned with the linguistic analysis of vocabulary errors in the target language by classifying vocabulary according to its semantic and pragmatic significance. The aim of this project is to find grounds of such errors, which hopefully will contribute to wards improving student interpreters' skills.

\section{SEMANTIC THEORY AND INTERPRETATION}

\section{Language acquisition and vocabulary}

Because at the time of interpretation training students are still learning more vocabulary, it is the wrong selection of vocabulary that hinders the interpreted message from 
being precise; errors caused by a wrong selection are acutely related to the learning process of vocabulary. Thus the concept of vocabulary learning in a second language is worthwhile to look at, in order to draw inferences on causes of such errors.

American Structuralism in the 1930's and onwards, had an influence on many linguistic interests. In language acquisition, too, the foremost concern was not just learning vocabulary, but rather mastering its sound system and its grammatical structure. This approach is embodied in Fries' (1945) statement that learners need enough basic vocabulary to practise the syntactic structures. He classifies words as:

1. function words;

2. substitute words;

3. words of negative/affirmative distinction;

4. content words.

According to him words belonging to the first three categories and some of the fourth are considered basic words; content words are cumulative, and necessary to practise learned structures. After this structural phase, learners proceed through three stages: the learning of vocabulary for production, the expansion of vocabulary for recognition and finally the learning of vocabulary for special areas of experience (Carter and McCarthy 1988: 40).

With regards to the expansion of vocabulary learning, the recent trend in linguistics is to move away from Structuralism, and be more concerned with discourse levels. The latter are to do with contextual or collocational relations between vocabularies, between vocabulary and its context(s). To acquire a word therefore means to know all of its semantic and pragmatic fields ( $c f$. Anderson and Shifrin 1980, Channel 1984, Cowie 1981, McCarth 1984).

Coulthard (1985: 147) cites Canale's (1983) definition of communicative competence as the composition of grammatical, sociolinguistic, discourse and strategic competences. All these competences are necessary for learners to acquire, and vocabulary learning conforms to them. And then, for the first time a particular word is acquired. As is often said, learning is a process but acquisition is the end result.

At this point, language acquisition in general distinguishes between productive and receptive use of vocabulary. However, because the topic here is interpretation in which vocabulary should be always ready to be used for message transmission, acquisition of vocabulary in this case is concerned with its productive aspect only. Thus, to know the meaning of a word here means to know its grammatical, semantic and pragmatic features, which at the same time should mean an easy access to production in speech. The knowledge of those features will lead to correct and appropriate interpretation.

Bearing in mind that the present work is concerned with interpretation skills, I classify vocabulary acquisition as follows:

1. phonological aspect;

2. morphological and syntactic functions;

3. semantic functions;

(a) componential aspect;

(b) structural collocation: selectional restriction;

(c) semantic collocation: syntagmatic affinity;

4. pragmatic functions;

(a) pragmatic constraints in contexts, situations and/or topics;

(b) stylistic constraints. 
There may be further aspects to be considered in language acquisition in general (for instance strategic aspects), but the above-mentioned are the fundamental and paramount requirements in manipulating vocabulary in interpretation.

Theoretically, errors may occur at any stage of the four aspects above, but from the data, phonological, morphological and syntactic aspects of vocabulary seem to be most unlikely to lead to errors. This is because interpreters produce grammatical structures within their knowledge, i.e. produced structures are under their control. Also, interpretation is conducted verbally so that if the pronunciation of a word is not known, they simply do not produce it.

The componential aspect of semantic functions is often discussed in semantic theory in terms of componential analysis by using semantic features (e.g. Bolinger 1975: 192-198, Leech 1974: 96-99, Palmer 1981: 108-114). For instance, the meaning of man can be expressed by combinations of the following features:

man : [+HUMAN, +ADULT, +MALE]

The formula of componential analysis is often said to refer to cognitive or conceptual meaning. In language acquisition the translated meaning is the first stage if a particular word is not known to a learner. Componential meaning conforms to this stage. In this project, errors of this type rarely occurred. In the same way as the first and second aspects above, interpreters simply do not produce vocabulary if they are not familiar with its conceptual meaning in the target language. For example, if they hear the word hut in English and do not know the translated word koya in Japanese, they cannot produce it; instead they might produce another word which explains hut (e.g. tiisana ie = small house). Thus, errors of this type rarely occur.

It is therefore structural collocation, semantic collocation, pragmatic constraints and stylistic constraints which hamper the interpretation process. (The other aspects above are of course still important for students to acquire new vocabulary.) In the following each term is explained.

\section{Semantic and pragmatic constraints}

\section{Structural Collocation: Selectional Restriction}

' $\mathrm{X}$ ' and ' $\mathrm{Y}$ ' (' $\mathrm{X}$ ' and ' $\mathrm{Y}$ ' are variables) are structurally collocational if ' $\mathrm{X}$ ' requires a certain feature which ' $Y$ ' has. This semantic feature is obtained within a syntactic structure and does not refer to discourse level. It is argued by McCawley (1970) that selectional restriction is not independent in semantic analysis, but is predictable from the meaning of a lexical item. Unlike semantic collocation below, structural collocation is predictable in each lexical item itself, because it has an inherent semantic feature. For example, die can occur with John as in John died, but not with the spoon as in *The spoon died. This is because die requires a subject which has a semantic feature [+ALIVE]. The spoon does not have this feature; it therefore cannot be structurally collocational with die.

\section{Semantic Collocation: Syntagmatic Affinity}

' $\mathrm{X}$ ' is easily associated with ' $\mathrm{Y}$ ' because of its frequent and semantic relevance to ' $Y$ '. For example, the word candle is easily associated with the word flicker, and dog with bark.

Collocation is defined as an aspect of lexical cohesion which embraces a relationship between lexical items that regularly co-occur. Miller (1978), for instance, does not differentiate between structural and semantic collocations. However, there is a definite difference between them. That is, structural collocation is a type of lexical cohesion by 
which two lexical items are structurally related because the feature of the one accords with that of the other. Semantic collocation on the other hand is a type of lexical cohesion which is occurrence relevance between two lexical items. Unlike structural collocation, semantic collocation does not bind two items with a semantic feature. Only by syntagmatic association are they collocational.

\section{Pragmatic Constraints in Contexts, Situations and/or Topics}

Synonymous words ' $\mathrm{X}$ ' and ' $\mathrm{Y}$ ' are not always used in the same contexts. ' $\mathrm{X}$ ' is selected rather than ' $Y$ ' because of its appropriateness in a given context. This is a situational constraint. For example, require occurs in a certain context such as a formal statement, 'This requires further investigation', but not in a conversational context, 'Jimmy, would you require more sugar in your coffee?'

This project dealt with conference interpretation. The topic is medicine. The speech was made by a doctor to other doctors at a conference. This situation requires vocabulary selection with the following pragmatic constraints:

less emotive, less local, less literary, least child-likes, more professional, more evaluative and more propositional

I call this word-level selection. As the content of a speech becomes more formal and abstract, more Sino-Japanese terms (in contrast with native Japanese terms) are used. Mizutani (1977) and Miyazima (1977) present, in their research reports, that the occurrence of Sino-Japanese terms is much higher in abstract texts. They argue that SinoJapanese terms are more specific in that they offer exact referential meaning and are used in a narrower context. In contrast, the semantic domains of native-Japanese terms are more elusive, thus more general, and have overlapping meanings. Therefore, the consistent use of native-Japanese terms often has an obscure effect in discourse. In the case of specialized fields such as conferences, Sino-Japanese terms are inevitably used.

Often technical terms (or jargon) are referred to when describing vocabulary in a specialized field. But technical terms are not our concern here. Rather, to conform to the given situation, vocabulary on a certain level is selected, and if too general a vocabulary is selected, it is considered a violation of pragmatic constraints.

This type of constraint exists in every language, and usually vocabulary is categorized according to its degrees of formality; then, it is classified as colloquial, informal, formal or archaic. Generally this classification is dealt with as a stylistic aspect. Or, conversely, stylistic constraints are integrated into pragmatic constraints. However, I classify the one as independent of the other. This is because in Japanese, although some formal words can be related to stylistic nature, there are honorific terms which primarily control the style of a context. This means that honorifics create a certain level of speech, but they do not necessarily control the usage of a certain vocabulary which is compelled to be produced by its pragmatic situation. Honorifics can exist wherever there are social interactions between people, whether in conference, or in normal conversation. On the other hand, certain levels of words usually designated by Sino-Japanese terms are always required to be used in a specialized field. Therefore, even if stylistic constraints are eliminated, the question of word-level selection remains.

\section{Stylistic Constraints}

This is principally concerned with the usage of honorifics. In the case of conference interpretation, the following points should be considered, and appropriate honorifics should be used. 
1. To be polite to the audience, but not too humble because the speaker is invited as a guest.

2. No honorifics are used for human beings if they are quoted unless some emotional attachment to them is to be shown.

3. To avoid colloquialism one should refrain from being too familiar towards the audience.

4. Once a certain level of honorifics is selected, it is more appropriate to maintain the same level throughout the speech unless some intentional effects by using different levels are aimed at.

These points are a summary of the findings of this project as well as, of a previous one by $\mathrm{Ng}$ and Obana (submitted, 1991). Point 4 was pointed out by five professional experienced interpreters (personal interviews at Inter-Osaka in Japan, in January, 1991). Because the primary importance of interpretation is to convey correct messages, anything that interferes with their understanding should be avoided. Honorifics do not contribute to the content, but function only as the speaker's intentional strategy to allow his/her message to be favourably received by the audience. Thus, to avoid distracting them from concentrating on the message, it is better to maintain the level of honorifics.

Honorifics in Japanese are a complex system, and their forms vary according to the social relationship between the speaker, the listener and the referent. However, conference style does not need the whole range of this system. As far as utterances directed to the audience are marked by honorific terms which are neither supreme nor too humble but frequently used standard terms, the interpreter does not fail to achieve stylistic appropriateness.

\section{METHODOLOGY AND FINDINGS}

\section{Method}

To conduct this project, eight informants were asked to interpret. Five of them are students of the Interpretation and Translation Course in the postgraduate studies, one is a graduate from this course (1990), and two are currently professional interpreters. Five of the eight are English speakers and the rest are Japanese speakers. They are all excellent in both Japanese and English. The speech is about transplantation and it is delivered by an Australian doctor to Japanese doctors at a medical conference held in Japan in 1990. Before the recording, the background of the issue of transplantation was explained to the informants. Afterwards, they were asked to interpret consecutively from English to Japanese. All the medical terms such as cardiac arrest, myocardial infarct known as technical terms were given to the informants to avoid unnecessary interruptions. Since technical terms are normally studied in advance for an actual conference too, information on these terms should not go astray from the reality. All the interpretations were recorded and then transcribed, and errors were extracted to be analyzed according to the classification made in the previous section.

\section{Findings and discussion}

In spite of some anticipation that native speakers of Japanese might not evidently show types of errors of our concern, though they might make other types of mistakes (e.g. structure grasping in the source language, misunderstanding English words), they made errors similar to those of English speakers regarding selection of vocabulary with certain pragmatic functions. That is, they are equally unaware of pragmatic constraints, i.e. situational constraints, due to the situation of medical international conference, and of stylistic constraints, i.e. the use of honorifics. However, the same informants rarely produced errors of semantic constraints, i.e. collocational contraints whether structurally or semantically. This is shown in Fig. 1: 


\begin{tabular}{|l|c|c|c|c|c|c|c|c|c|}
\hline & \multicolumn{3}{|c|}{ Japanese } & \multicolumn{5}{c|}{ English Speakers } & \\
\cline { 2 - 11 } & A & D & E & B & C & F & G & H & Total \\
\hline (a) Structural Collocation & 0 & 1 & 1 & 5 & 2 & 3 & 4 & 6 & 22 \\
\hline (b) Semantic Collocation & 0 & 0 & 1 & 2 & 4 & 3 & 2 & 3 & 15 \\
\hline (c) Pragmatic Constraints & 1 & 4 & 6 & 7 & 9 & 8 & 8 & 7 & 50 \\
\hline (d) Stylistic Constraints & 2 & 2 & 4 & 4 & 5 & 8 & 4 & 4 & 33 \\
\hline \multicolumn{1}{c|}{ Total } & 3 & 7 & 12 & 18 & 20 & 22 & 18 & 20 & \\
\hline
\end{tabular}

Figure 1

Errors

The number of errors in Fig. 1 does not necessarily determine the quality of interpretation. Errors were counted only when they occurred in relation to the source message. This is because some informants were occasionally incapable of interpreting, which resulted in either omitting phrases or producing incomprehensible messages. Such cases are not evident in Fig. 1. The reiterated error of the same term was counted as one. Also, when completely wrong messages were produced, that is, extreme content distortion occurred, they were not considered types of errors in this study, and were excluded from the data analysis.

As far as the overall quality of interpretation is concerned, Informants A and B are the best despite B's larger number of errors as compared with $\mathrm{D}$ and $\mathrm{E}$.

The following are examples of errors in each type.

Structural collocation:

EX. 1...criteria for pronouncing a patient as brain dead...
(A) 选死飞判定才る基染 noosi to hantei suru kizyun
(B) 胸死代と洪定する染 noosida to kettei suru kizyun

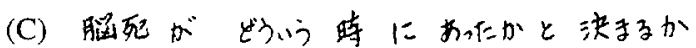 noosi ga dooiuu toki ni attaka to kimaruka

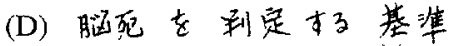
noosi wo hantei suru kizyun

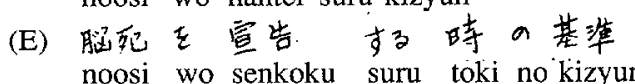

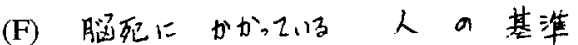 noosi ni kakatteiru hito no kizyun

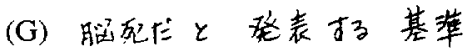
noosida to happyoosuru kizyun
(H) 肧死 と診断拉基萑 noosi to sindansuru kizyun 
The problem here is the relation between noosi ( $=$ brain death) and its verb pronouncing. All the informants understood the meaning of pronouncing and its Japanese counterparts all targetted the cognitive meaning. However, Informants E, F, G and H erred because their verbs in Japanese were not structurally collocational with the noun brain death. Senkokusuru in E's interpretation should collocate with an item which is related to crime. Thus, this verb is normally used for court verdicts. Kakatteiru in F's case should collocate with an item which has a feature [+LIVE]. Brain death has a feature [-LIVE] so that it cannot occur with that verb. Informant G's happyoosuru should occur with an item which is publicly announced such as an announcement to the press. Informant H's sindansuru should collocate with an item which has a feature [+LIVE]. Normally this verb is used as a diagnosis for living patients who are suffering from some disease.

EX. 2...the public have the confidence that the medical profession knows what it is doing....

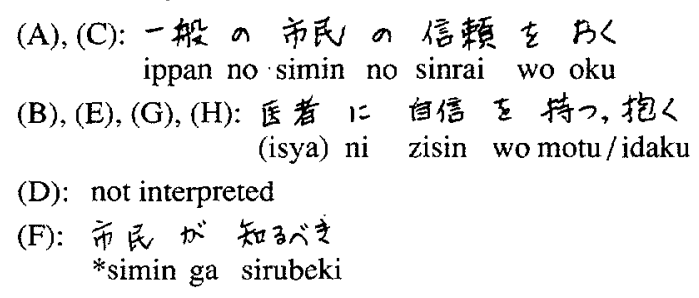

This is a problem of collocational usage of sinrai and zisin. Both mean confidence. The former will occur with an item which contains [+THIRD PARTY] or the like, whereas the latter collocates with an item of [+SELF]. While one is 'to trust someone else', the other is 'to be confident in oneself'.

\section{Semantic Collocation}

EX. ...cadaver organ donors...
(A), (B): 䑏器 zooki no doonaa

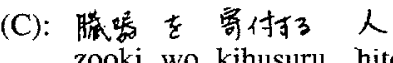 zooki wo kihusuru hito

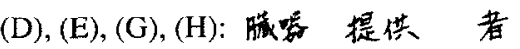 zooki teikyooo -sya
(F): not interpreted

The problem lies in the interpretation of donors in relation to cadaver organ. Informants A and B used a loan word doonaa which is accepted in modern Japanese. Kihusuru by $\mathrm{C}$ is associated with donating money or goods to a charity organization, but should not collocate with a person donating his cadaver organ. Teikyoosuru is most appropriate in this context.

\section{Pragmatic Constraints}

EX. 1...death can be diagnosed when....

$$
\begin{aligned}
& \text { (A): 死 } 0 \text { 定裁 } \\
& \text { si no teigi }
\end{aligned}
$$




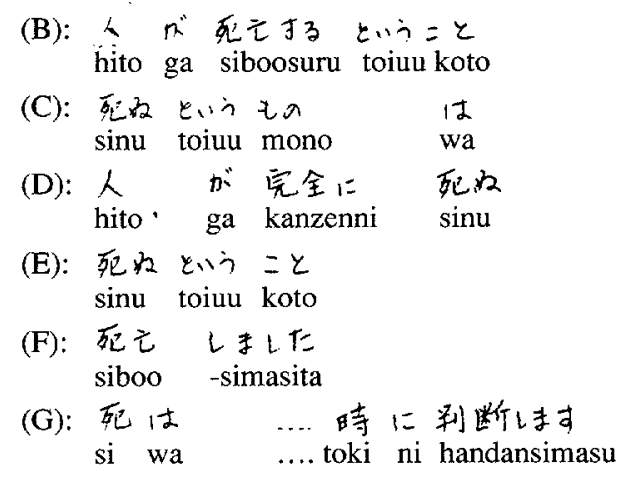

As is mentioned in the section on semantic theory and interpretation, a medical conference is a situation which imposes certain levels of vocabulary. Except for $A$ and H's si (= death), which is most appropriate for doctors' usage, the others are either too general (B and F) or too colloquial (C, D, E, G).

EX. 2....when the heart has stopped and breathing has ceased,...

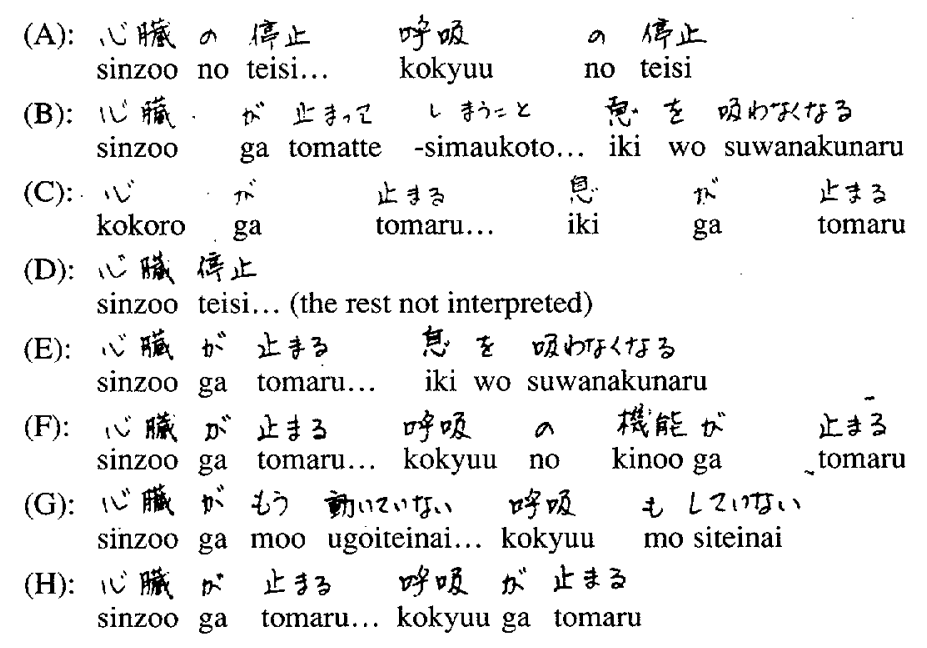

Although the heart, stop, breathing and cease are neither technical terms nor special proprietary terms in English, they should be interpreted into Japanese terms which render a particular pragmatic function. In this respect Japanese is more demanding in the selection of specific vocabulary. Informant C's kokoro still means heart, but this is too literary; it is normally used in a poetic situation. Tomaru (= stop) is too general for a medical speech. So are $i k i$ (breathing) and suwanakunaru (= cease breathing) although they are all correct grammatically and semantically. Informant A's interpretation is most appropriate. All the terms used by A are Sino-Japanese words which are perhaps hardly used in normal conversation; they occur in a limited situation.

\section{Stylistic Constraints}

As is mentioned in the section on semantic theory and interpretation, stylistic constraints are more conspicuous in Japanese because of the usage of honorifics. First, the speaker ( $=$ the interpreter) should be deferential to the audience while he/she is careful 
enough not to be too humble. Especially if the content is directed towards the audience, honorific usage must occur. In the speech, there were some phrases which referred to the audience.

EX. ...you, the medical leaders in your community, must be in the forefront of developing the code...

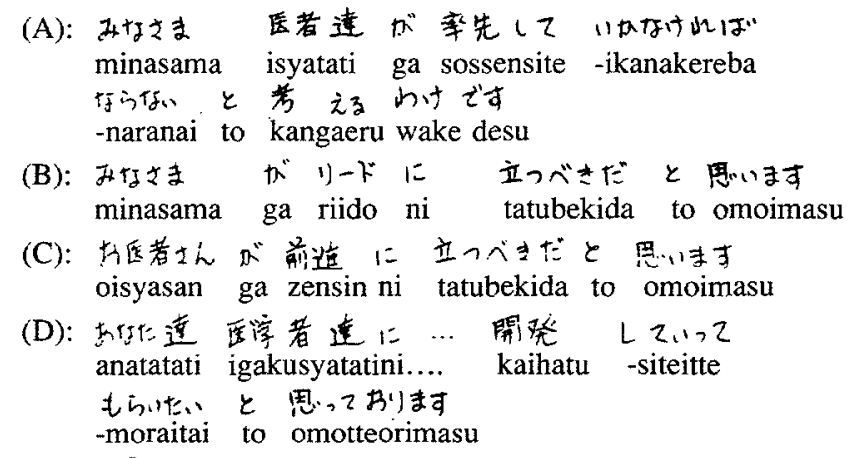

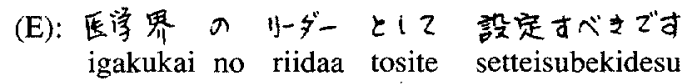
(F):日本a医者は作棠にたずさわるべきだ nihon no isya wa sagyoo ni tazusawaru -bekida と思います to omoimasu

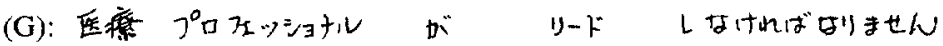 iryoo purohuessyonaru ga riido -sinakerebanarimasen

$(\mathrm{H}):$ こに集ま,2、る人は先端に立たて子 kokoni atumatteiru hito wa sentan ni tatana けルげすリません -kerebanarimasen

None of the interpreted messages are honorifically-marked. Only A and B refer to you as minasama which means everyone with a honorific marker sama, but the verb 'be in the forefront of' is not deferential in either interpretation. Informant D's anatatati (= you all) is provocative, because in Japanese the term directly referring to you is avoided or omitted (i.e. subjectless in the sentence) unless the conversation occurs between close friends in the same age group or from the senior to the junior.

The auxiliary must in English here is interpreted as bekidesu (= should) or nakerebanarimasen (= have to). However, these auxiliaries are too strong in the sense that the Australian doctor is merely suggesting to the Japanese audience to do an action. Informant D's siteittemoraitai (= want you to do...) also sounds demanding.

Honorifics are hard to produce even in every day conversation. If the conversation is heated, lengthy honorific terms are rather an obstacle to convey messages. Even more so in interpretation because of an instant conversion from one language to another under the extreme time pressure. And yet it is inevitable to use certain honorifics not to provoke the audience. Otherwise, the speaker will be considered as either rude or arrogant, which results in disqualifying the interpreter for his / her inappropriate use of honorifics.

From the previous work ( $\mathrm{Ng}$ and Obana, submitted 1991) and this project, it is found that informants tend to attach honorific marking to human beings and their actions although they are quoted, thus, considered as factual. For example, if the context is about patients in general, there is no need to interpret it as kanzya-san (san = polite). This is a 
typical error among the English speakers. Also, it is notable that the informants used very colloquial terms such as tyanto (should be sikkarito = adequately), -sinakutya (should be sinakutew $a=$ must do). These colloquial terms were successfully avoided by the Japanese speakers. The errors by the Japanese speakers in Fig. 1 were normally found in utterances which refer to the audience (such as the example above) or which are the speaker's tentative suggestions. The Japanese speakers may know the usage of honorifics but in the interpreting situation the knowledge remains receptive. Or, simply they are still not capable of handling certain honorifics.

\section{CONCLUSION}

Interpretation training is rather a special stage of language learning. Although students have already achieved a highly advanced level in a second language, the course training involves more vocabulary leaning, which at the same time should be made as productive from receptive knowledge. What is more, under the extreme time pressure, while understanding the underlying meaning of messages, interpreters should be ready with productive knowledge of vocabulary, and with knowledge of all of its semantic and pragmatic fields. It is natural, then, to assume that there are many factors that hamper the production of appropriate vocabulary. The present work focusses on vocabulary errors and analyzes them in terms of their linguistic significances. This can go a certain way to achieve improving student interpreters' skills. But it does by no means indicate that only by knowing such significances students will achieve perfect vocabulary selection. The process of learning a second language is greatly related to the mechanism of our brain. Yet, we have at the present time very little information of how human memory functions and of how production mechanism pertains to vocabulary selection. The project here is only one way of approaching our goals.

The findings of this work draw our attention to the point that in training students, especially from the native language into a second language, trainers should keep reminding students of the variety of semantic fields of vocabulary. In the case of Japanese, even native speakers produce errors because of their unawareness of, or naive attitudes towards, pragmatic constraints, i.e. pragmatic collocation and stylistic constraints. As is pointed out, the usage of certain levels of Sino-Japanese terms and honorifics is still to be learned by native adult speakers. This makes the learning of a second language more complex and difficult. Yet, to obtain our goal of raising a professional interpreter, it is both the trainers' conscious efforts and the trainees' acute awareness as to what are the shortcomings in the present course training.

\section{REFERENCES}

ANDERSON, R. C. and Z. SHIFRIN. (1980): "The Meaning of Words in Context", Spiro, R. J., B. C. Bruce and W. F. Brewer (Eds), Theoretical Issues in Reading Conprehension, Lawrence Erlbaum Asso. Publishers, pp. 331-348.

BOLINGER, D. (1975): Aspects of Language (Second Edition), Harcourt Brace Jovanovich, Inc.

CANALE, M. (1983): "From Communicative Competence to Communicative Language Pedagogy", Richards, J. and R. Schimidt (Eds), Language and Communication, Longman, pp. 2-27.

CARTER, R. and M. McCARTHY (1988): Vocabulary and Language Teaching, Longman.

CHANNEL, J. (1981): "Applying Semantic Theory to Vocabulary Teaching", English Language Teaching Journal, Vol. 35, No. 2, pp. 115-122.

COULTHARD, M. (1985): An Introduction to Discourse Analysis, Longman.

COWIE, A. P. (1981): "The Treatment of Collocations and Idioms in Leamers" Dictionaries", Applied Linguistics, Vol. 2, No. 3, pp. 223-235.

CRUSE, D. A. (1986): Lexical Semantics, CUP.

FRIES, C. C. (1945): Teaching and Learning English as a Foreign Language, University of Michigan Press. 
HU, G. (1990): "An Exploration into Sci-tech Interpretations: Abstract Interpretation Approach", Babel, Vol. 36, No 2, pp. 85-96.

LARSON, M. L. (1984): Meaning-based Translation, University of America Press.

LEECH, G. (1974): Semantics, Pelican Books.

McCARTHY, M. J. (1984): "A New Look at Vocabulary in EFL", Applied Linguistics, Vol. 5, pp. 12-22.

McCAWLEY, J. (1970): "Where do Noun Phrases Come from?", Jacobs, R. A. and P. S. Rosenbaum (Eds), Readings in English Transformational Grammars, Ginn, pp. 166-183.

MILLER, G. A. (1978): "Semantic Relations among Words", Halle, M., J. Bresnan and G. A. Miller (Eds), Linguistic Theory and Psychological Reality, The MIT Press, pp. 60-118.

MIYAZIMA, T. (1977): "Goi no taikei" (The system of vocabulary), Oono, S. and T. Shibata (Eds), Goi to Imi (Lexical items and their meanings), Nihongo, Iwanami shoten, No. 9, pp. 3-41.

MIZUTANI, S. (1977): "Goi no Ryooteki Koozoo" (The quantitative structure of vocabulary), Oono, S. and T. Shibata (Eds), Goi to Imi, Nihongo, Iwanami shoten, No. 9, pp. 45-86.

NG, B. C. and Y. OBANA (submitted, 1991): "The Significance of Speech Levels in English-Japanese Interpretation", submitted to The Interpreters' Newsletter, University of Trieste.

PALMER, F. R. (1981): Semantics, Second Edition, CUP.

SELESKOVITCH, D. (1978): Interpreting for International Conference, Pen and Booth. 